\title{
Reaching out with rugby role models to inspire literacy in young children: Informing hybrid pedagogy
}

Hannelie du Preez ${ }^{a}$, Donna Hannaway ${ }^{b}$, Ina Joubert ${ }^{b}$ and Francinah Masolac

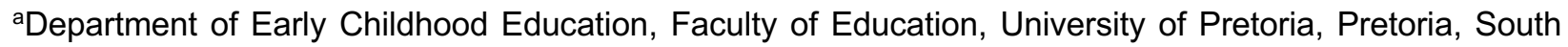
Africa; 'bepartment of Early Childhood Education, School of Teacher Education, University of South Africa, South Africa; 'Student, Department of Early Childhood Education, Faculty of Education, University of Pretoria, Pretoria, South Africa

\section{Vol 1 No 12019}

ISSN: 2788-6298

DOI: https://doi.org/10.35293/tetfle.v1i1.63

\begin{abstract}
Children are exposed to influential role models, such as parents, peers, teachers, fictional characters and humans in virtual and physical environments. Utilising role modelling as a teaching approach or rich teaching resource not only appeals to the social learning preference of a young child but also supports teachers in reaching out to virtual and physical communities to enrich literacy learning experiences. The perspective of role models to promote acceptable social and academic behaviour in young children has progressively introduced scholarly views on the achievability and importance thereof in education and its applicability as a hybrid pedagogy. With rapid technological advancements and increased access to the Internet, an integrated platform is provided which teachers can benefit from when incorporating role models to help cultivate responsible social and academic behaviour. In this study, we implemented a literacy programme - the Reading, Rugby and Responsibility project - as a community project to improve our understanding of how rugby students, as role models, can intentionally inculcate responsible social and reading behaviour in Grade 3 children. We aligned the outcomes of the project with the Community of Inquiry framework to hypothesise the value and feasibility of using role models as a hybrid pedagogy and resource in early childhood education. We utilised a qualitative case study design and purposefully selected five rugby students to interact with 35 Grade 3 children at an inner-city primary school in Pretoria. The data generated from informal discussions with the rugby students and reflections of their experiences, as well as the children's narrative accounts and drawings, were thematically analysed. The findings revealed that children yearn to engage with role models and be part of a community. Further investigation on how the Community of Inquiry framework can inform and utilise role modelling as a hybrid pedagogy and resource is beckoned and recommended.
\end{abstract}

Keywords: role modelling, responsible reading behaviour, responsible social behaviour, rugby, sports students, young children, Community of Inquiry, hybrid pedagogy

CONTACT Hannelie du Preez@ hannelie.dupreez@up.ac.za 


\section{INTRODUCTION AND BACKGROUND}

Mindful role models can be a powerful form of education, and with the expansion of social media, young children are more likely to observe behaviour, norms, values and knowledge of real-life and virtual characters who might become influential and potential role models. Children are susceptible to imitation, and Zirkel (2002) emphasises the important impact that role models make on the development and education of the youth. International scholars have advanced our understanding of the importance of sports and sports role models in inspiring socially acceptable behaviour (Allenders, Cowburn \& Forster, 2006; Gould, Collins, Lauer \& Chunghave, 2007; Gordon, 2010; Camiré, Trudel \& Forneris, 2012). Utilising role models as a teaching approach and mindful sport role models as resources can potentially transmute young children's views on acquiring responsible social and academic behaviour and actualise their potential and cultivate citizenship (Allenders et al., 2006; Gould \& Carson, 2008). As significant resources, they can purposefully intercede and cultivate responsible social and educational behaviour to the benefit of young children and the society in which they function (Allenders et al., 2006; Gould \& Carson, 2007).

We argue that collaboration with role models when constructing a learning experience not only benefits the teacher but also introduces the child to rich and diversified learning experiences. The holistic development of the young child in the 21 st-century warrants teachers who can creatively collaborate with communities, utilise computer software and technological devices and introduce physical and virtual role models to the classroom. Sensitising young children to recognise appropriate and positive real-life and virtual role models has become a $21^{\text {st }}$-century life skill. It is vital for young children to apply their knowledge about role models and sustain their responsible social and educational behaviour, especially when confronted with destructive or harmful media and social situations.

We introduced the Reading, Rugby and Responsibility (RRR) project, firstly to enquire how the intentional and physical participation of children in sports, under the counselling of a mindful sports role model, can potentially cultivate social and academic responsibility. 


\section{H. DU PREEZ ET AL.}

Moreover, we contemplated how the RRR project could potentially characterise a hybrid Community of Inquiry ( $\mathrm{Col}$ ) framework, to be utilised by teachers to invite real-life as well as virtual role models into the classroom to promote responsible social and educational behaviour.

\section{EARLY CHILDHOOD DEVELOPMENT AND EDUCATION}

According to Zirkel (2002), children grow up accepting their ethnic backgrounds, religion, socioeconomic status, family structures and communities, which they are cultivated in by means of observing and imitating role models. This is especially necessary for a democratic society, where a sense of nationhood needs to be cultured for the democratic state to function (Department of Basic Education, 2011). Becoming socially and academically responsible is not only a life skill but also a medium through which one can reach expression, providing the young child with the opportunity to evolve into a responsible and valued citizen who can demonstrate a deep-seated sense of fairness and a value-based moral code (Laker, 2000). The intended curriculum envisions young children (Grade $R$ to Grade 3 ) to acquire specific knowledge, skills and values that will shape them in becoming social, moral and educated citizens for the benefit of a democratic South Africa (Department of Education, 2011).

Social and moral responsibility often use physical activity as a vehicle for encouraging responsible behaviour in young children (Laker, 2000). Kavussanu (2006) studied the behaviour of young children's participation in rugby-learning experiences and found that such physical activities enhanced pro-social behaviour, helped to build character and instilled a sense of responsibility within young children (i.e. helping an opponent in a lineout or kick). Kavussanu (2006) further explains that high levels of morality during sports activities can be associated with a high frequency of pro-social behaviour and a low frequency of antisocial behaviour (i.e. deliberately avoiding a high tackle or injuring an opponent). Hellison (2011) found that children who participated in sports, started behaving more responsibly, became more caring and demonstrated sensitivity and responsiveness to the wellbeing of others. Clarke, Osborne and Dugdale (2009) found that children who enjoy reading have a wide range of people who inspire reading, 
including family members, celebrities and sportspersons. The children were of the opinion that their role models could promote reading engagement by recommending material or explaining why reading is important (Clarke et al., 2009).

According to Hellison (2011), young children acquire personal and social responsibility by being introduced to a learning experience where life skills, language and values are integrated with real-life physical activities in the presence of mindful role models. There is a common understanding among scholars that young children best acquire knowledge, skills and values by being actively and physically engaged in their learning experience (Eley \& Krik, 2002; Laker, 2000). The holistic development of the young child warrants a holistic learning experience, such as integrating physical experiences, language for communication and thinking, and social opportunities to help acquire and shape responsible behaviour (Bee \& Boyd, 2004; Owens, 2002). In South Africa, the curriculum for the young child adopts an integrative pedagogical approach that encourages and guides teachers to construct learning experiences that fuse knowledge bases of language, mathematics and life skills to promote young children's holistic development and desire to become lifelong learners (Department of Education, 2011).

\section{THE NATURE OF ROLE MODELS}

Role models, otherwise described as heroes or mentors, form part of humans' daily lives, and having a significant impact on the beliefs, views and actions of individuals, are often invited to convey a message to the target group(s) to encourage change in behaviour (Payne, Reynolds, Brown \& Fleming, 2014). The role model concept refers to someone being exemplary, who has laudable values and is worthy of imitation. Role models are likely to be perceived as socialising agents; their presence is significant in the early years for shaping the observers' behaviour and thinking processes (Bee \& Boyd, 2004; Payne et al., 2014). Role models (e.g. teachers, spouses, parents, peers, mentors, movie stars, pop stars, animated characters and sports heroes) inspire individuals and groups by sharing knowledge, experiences and advice for future endeavours that rely on personal contact and building a relationship (French \& Pena, 1991; Payne et al., 2014). 


\section{SOCIO-COGNITIVE THEORY}

The socio-cognitive theory (SCT) originated from the work of Edwin B. Holt and Harold C. Brown, who hypothesised the value of imitation, using animals. The value of utilising role modelling as a teaching approach has been theorised by psychologist Albert Bandura $(1977,1986)$, who proved a direct correlation between a person's perceived self-efficacy and behavioural change. He further explicated that the task of learning is dreary if it depends solely on children's own actions. According to Sanderse's (2013) interpretation of Bandura's work, a considerable amount of learning about behaviour, attitudes, values and beliefs takes place when children observe others and the consequences of the actions of others. According to their understanding of SCT, Payne et al. (2014) and Sanderse (2013) claim that children pay attention to role models, rely extensively on their encouragement and can encode, imitate or mimic observed behaviour. Payne et al. (2014) further explicate that the child's succeeding involvement in physical activity should rely on symbolic representations of words and images, the precise processes of interpreting and observing cues, as well as the factors that motivate the desired behaviour.

The counselling of mindful sports role models can serve as a motivator to young children through guiding, advising and coaching responsible social and academic behaviour (Bee \& Boyd, 2004; Payne et al., 2014). As the children adopt the new behaviour, the guidance of the role model is gradually reduced until the children can demonstrate responsibility for their proactive social and educational behaviour. According to Eley and Krik (2002), Hellison (2011) and Laker (2000), it is through interactions with sports role models that young children develop a sense of morality and pro-social behaviour, and internalise norms and values that inspire them to consider some acts as forbidden or undesirable and others as highly commendable. Examples of these are power sharing and decisionmaking, taking care of others, leadership, teamwork, fair play and physical and verbal conflict resolution. 


\section{CONCEPTUAL FRAMEWORK}

The Community of Inquiry ( $\mathrm{Col})$ is a framework that has attracted considerable attention at institutions of higher education that embark on a hybrid pedagogy. This framework not only serves the purpose of pursuing the value of collaborative learning but also assimilates communities in learning experiences (Garrison, 2007). Based on the work of Garrison, Anderson and Archer (2000), the Col framework accounts for three aspects crucial to learning, namely a social, a teaching and a cognitive presence.

According to Garrison (2007) and Garrison et al. (2000), "social presence" refers to the establishment of a personal and purposeful relationship between the teacher and the children, considering aspects such as effective communication and group cohesion. These authors maintain that within this presence, a sense of community is achieved when the children are working towards a collaborative goal through collaborative activities, benefitting from the perspectives of others.

"Cognitive presence" pertains to the collaborative and reflective effort initiated by the teacher with the children to explore, construct, resolve and conform to understanding as a community of inquiry (Garrison, 2007; Garrison et al., 2000). Thus it is a cycle of practical inquiry where the children progress from understanding the problem to being able to explore, integrate and apply, which signifies educational, behavioural change (Garrison, 2007; Garrison et al., 2000).

The focus of the "teaching presence" is to assure that the teaching construct is properly designed, facilitated and directly instructed, making the teaching presence a noteworthy contributor to children's satisfaction with the perceived learning by establishing and maintaining a sense of community (Garrison, 2007; Garrison et al., 2000).

The following illustration demonstrates how the Col framework has been applied to the RRR project. 


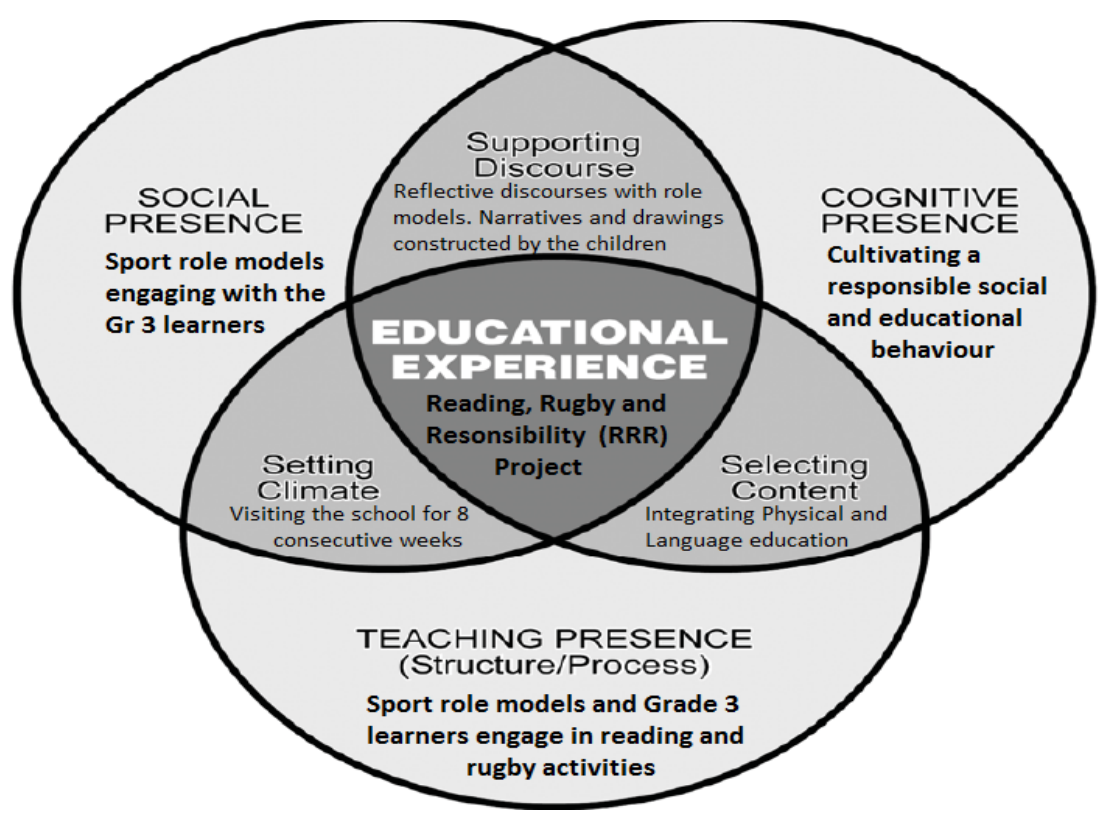

Figure 1: Community of Inquiry framework integrated with the Reading, Rugby and Responsibility project (adapted from Garrison et al., 2000)

As discussed earlier, the advancement of technology and easier access to the Internet unlock the possibility for teachers to incorporate a hybrid pedagogy such as the Col. This framework morphs social, cognitive and teaching presences into a rich environment full of educational experiences without sacrificing pedagogy and quality. The potential for teachers to reconnect with various communities of inquiry is, therefore, beckoned. The RRR project shaped our understanding of how rugby students, as mindful role models, can intentionally inculcate responsible social and reading behaviour in Grade 3 children. By implementing the RRR project, we were then able to align the RRR project outcomes with the Col framework and hypothesise the value and feasibility of using role models as a hybrid pedagogy and resource in early childhood education. Within the depicted illustration, we briefly refer to the interrogative sestet (e.g., what, when, where, why, who and how) which is discussed in more detail in the section to follow. 


\section{METHODOLOGICAL FRAMEWORK}

\section{Research design}

A research design guides researchers on how to conceptualise their research inquiry by considering aspects such as design, data generation, data analysis and inferences, thereby becoming a framework for developing an understanding of the phenomenon, the participants and the context (Denzin \& Lincoln, 2008). A qualitative research design, as a mode of inquiry, along with a case study design, was used to implement the RRR project. A case study design enabled researchers to explore a contemporary phenomenon within its real-life context when the peripheries between the phenomenon and the context are not obviously evident, and multiple sources of evidence are used (Denzin \& Lincoln, 2008). The designed case study was aligned with the Col framework to serve as a hypothesis of how the RRR project could be utilised as a hybrid pedagogy.

\section{Research site, population and sampling}

The context of the research environment represents multifaceted information. Firstly, the child participants primarily live in Sunnyside, Pretoria, which can be described as an inner-city neighbourhood, predominantly consisting of apartment blocks with limited physical space. Apartments in this neighbourhood can be described as self-contained housing units that occupy only part of a building, called an apartment building, an apartment complex, a flat complex, a block of flats or a tower block. Secondly, the research setting commenced at the child participants' school premises, which contain ample space for classrooms, administrative buildings and sports or recreational spaces. The population for this research inquiry comprises adult participants who are students at an institution of higher education and child participants from an inner-city school. A small sample of adult and child participants who adhered to specific characteristics were identified from this particular population group, using purposive and convenience sampling techniques. This sample consisted of five university sports students who acted as rugby role models to 25 Grade 3 children, approximately nine years of age. Due to the nature and size of the sample, we acknowledge that the findings cannot be generalised; instead, we put forth the value the RRR project holds to illustrate the importance of role 


\section{H. DU PREEZ ET AL.}

modelling as a hybrid pedagogy in the early years. Similarly, whether or not other sports role models would have had the same influence needs to be further examined.

\section{Ethical considerations}

Regarding the constitution of conducting just research on humans, we strictly adhered to the guidelines and principles of the Ethics Committee. We ensured the voluntary participation of all participants as permitted by the educational district, the school principal and the consent of the parents. To resonate the importance of developing a sense of community, the role models established rapport with the children by engaging with them over a period of eight weeks and progressively gained their trust and respect. Precaution was taken to assure the safety of the children by utilising role models who were competent in rugby coaching and had been trained in role modelling and conducting reading activities to young children.

\section{Trustworthiness}

Trustworthiness signals efforts taken by the researchers to ensure that the entire research process is conducted in a valid, credible and believable manner (Denzin \& Lincoln, 2008). In this study, trustworthiness was sought through conceptualising a detailed project and aligning it with the Col framework. Prolonged engagement, persistent observation and commitment to the success of the RRR project guided our effort to understand the congruence between the construction and the interpretation of the data. We also constructed a historic record of the entire RRR proceedings, which served as a way to control the quality of the findings. Concerning the data generation, various strategies were utilised as safeguards against bias in the findings. The researchers were indirectly involved but refrained from interfering with the learning experience. As a team, we regularly collaborated to serve as an objective soundboard for one another's interpretation of the data. The constructed themes were peer-examined, and the participants' interpretations were considered. 


\section{Data generation}

We were motivated to obtain an in-depth understanding of the phenomena. Engendering such data required rigorous and creative data generation ideas as the involvement of the adult participants had to appeal to the child participants' interests. To illustrate how we empirically generated the RRR data sets and aligned the generated outcomes to the Col framework (see Figure 1), we will outline this section against the backdrop of the three presences, namely social, cognitive and teaching.

Constructing a "social presence" necessitated that the child participants should feel secure with the adult participants and that the envisioned activities should establish effective and open communication channels (Garrison, 2007). Social bonds had been shaped and developed over a period of eight weeks while striving towards a common purpose. The adult participants engaged with the child participants in sports and reading activities that were developmentally appropriate and interesting to young children. Generating a social presence enabled us to provide the child participants with a social setting and a mindful role model who modelled responsible social and academic behaviour to the children to emulate and potentially internalise the concept of responsibility with their value systems.

Creating a "cognitive presence" required discourse and sustained reflection in a critical Col (Garrison, 2007). We utilised rugby and reading activities to introduce the concept of social and academic responsibility and paired it with reflection and critical thinking activities in which the participants engaged. The adult participants took part in written and verbal reflections of their experiences of acting as the mindful role models of the Grade 3 children. The child participants created written and visual artefacts on their understanding of responsible behaviour, after the rugby and reading activities. To capture the setting of the RRR learning experiences, field notes of every rugby activity were recorded, and photographs were taken.

Garrison (2007) also emphasises the importance of sustaining a "teaching presence" by appraising the quality of the guidance to support learning. Interaction and discourse play 
a key role in higher-order learning; however, this is neither without a teaching design nor facilitation, instruction or leadership (Garrison, 2007). Every week a social and educational outcome was designed by the researchers and implemented by the adult participants at the school. Some of the respective activities were reading, listening to and role-playing stories, asking higher-order questions, learning about rugby positions, as well as scrumming, hooking, ball-handling, line-out throwing and passing activities.

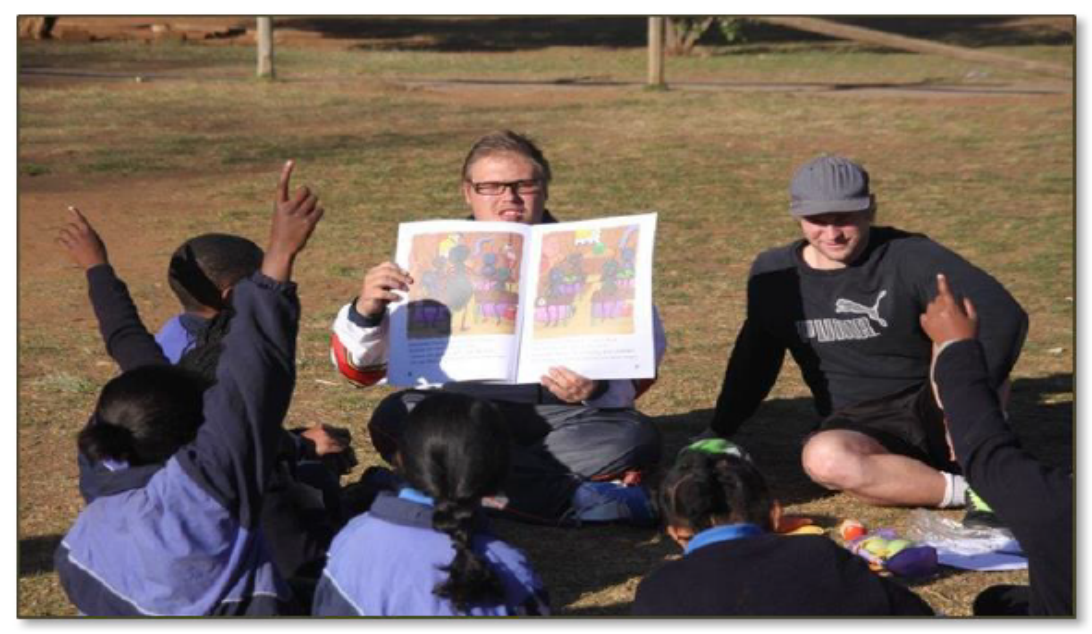

Illustration 1: Sports role models reading to and discoursing with the Grade 3 children

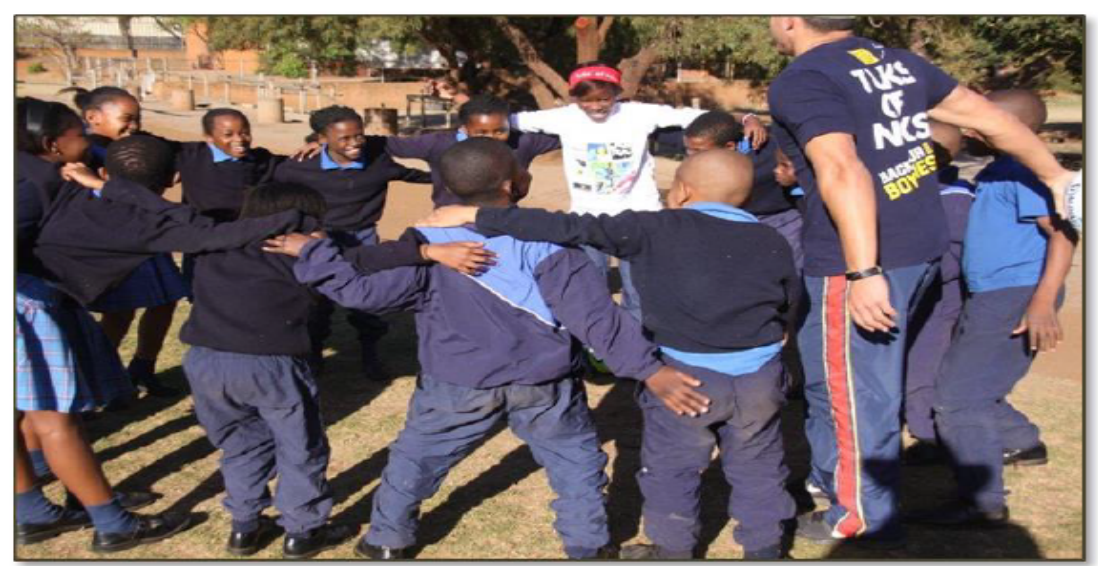

Illustration 2: Sports role models teaching scrumming to the Grade 3 children

The two illustrations capture two respective activities. The first photograph depicts two male role models reading to the child participants using a "big storybook" and allowing for interactive discourse. The second photograph depicts the introduction on how to take part in a scrum, as demonstrated by two role models. 


\section{Data analysis}

The purpose of analysing data qualitatively is to describe and make sense of the phenomenon and to answer the research problem that drives such an investigation (Denzin \& Lincoln, 2008). The data analysis implicates an iterative process of labelling, coding and grouping data to document the similarities and differences therein and summarising the message in the content (Denzin \& Lincoln, 2008). We systematically analysed the vast amount of data by familiarising ourselves with the different data sets, coding the data sets, identifying patterns, reviewing the identified patterns, defining and labelling each theme and constructing a report of our findings, using the derived and verified themes. Given the nature and purpose of the RRR project, the interpreted data yielded five overarching themes, namely teaching rugby, developing values, facilitating verbal and written language, enacting citizenship and becoming a role model, with respective sub-themes as indicated in Figure 2.

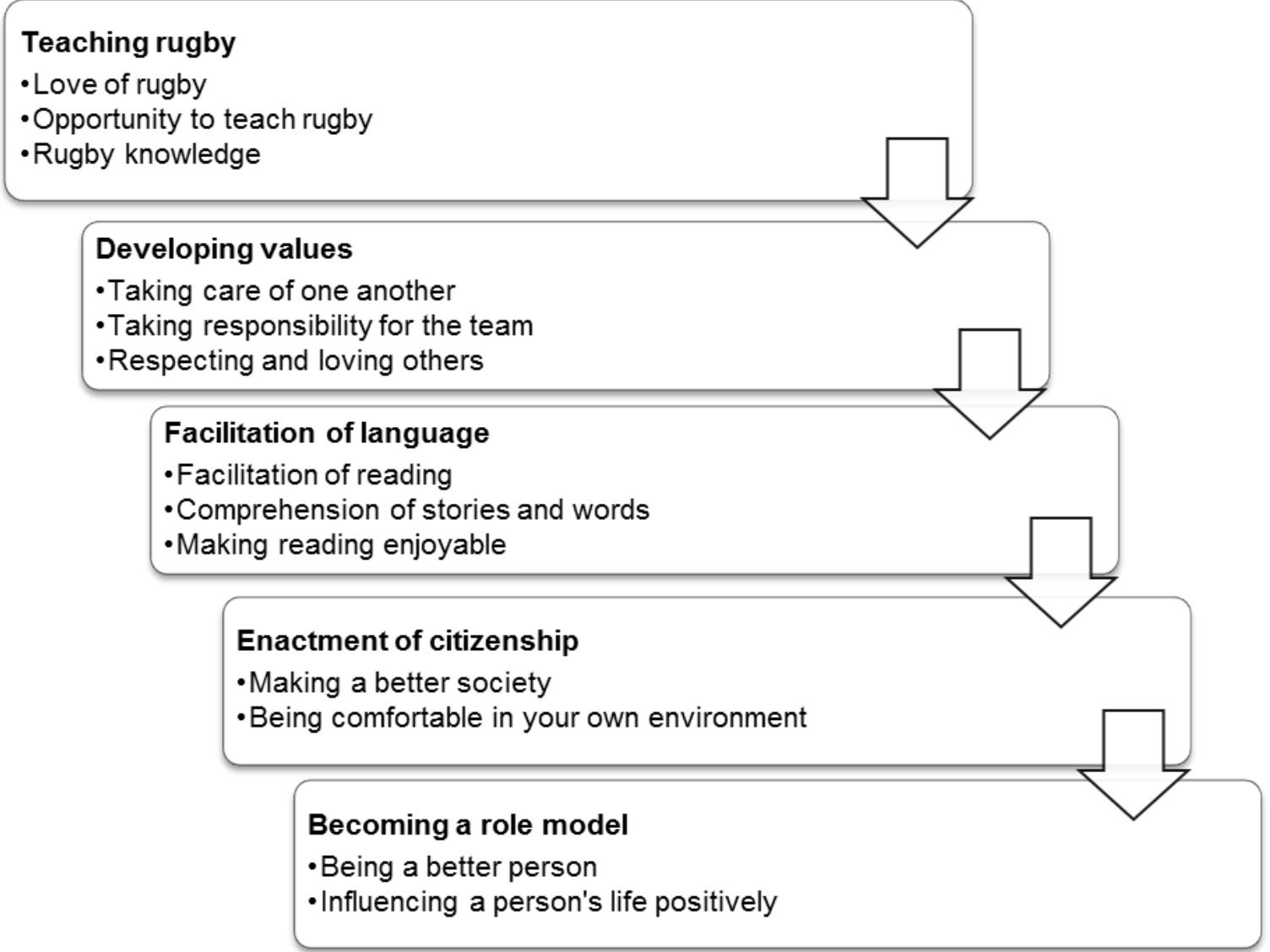

Figure 2: Overview of the themes and subthemes 


\section{H. DU PREEZ ET AL.}

The first theme, teaching rugby, contributed evidence of the love of the sport that provides enjoyment for both the sports role models and the Grade 3 children. The adult participants noted an opportunity and a responsibility to teach rugby, sharing their knowledge and skills with the children. In the second theme, dealing with developing values such as respect, care and responsibility, the child and adult participants highlighted taking care of one another, as expressed in the following statements: "Yes, I learnt to look after others and take care of each other" (RMB; 30) and "I am willing to go out of my way to do a good deed at least once a day. I was always there for them, taking care of them" (RMD; 2526). This notion was also reciprocally expressed and actioned during the child and adult participants' sessions. "They learn through rugby to take responsibility for their action. To be able to play a good and fair game. Yes, be responsible for every player" (RMB; 5356), "In rugby, we don't fight. We don't push... we are a team" (C2; 2) and "My responsibility is to learn how to play together with my team" (C20; 2), as well as "My responsibility is to do the right thing and to be good to others" (C23; 3). The facilitation of language comprised the third theme, which provided empirical evidence of the importance of making reading enjoyable through the novel facilitation of reading activities and rugby coaching. The adult participants expressed this as follows: "They [the children] seem to enjoy the stories and pictures which would make them want to read and enjoy reading" (RMB; 35), "...the stories tie well with responsibility teaching and teamwork" (RMA; 14) and "...the stories teaches [sic] the children discipline and respect" (RMD; 17). The child participants mentioned that a love for reading was developed, for example, "I love reading because rugby students bring nice books for us to read. They made me love reading very much" (C16; 3). The fourth theme, enactment of citizenship, and the empirical data generated the finding that the participation in the RRR project contributed to how the children could improve society: “...do your best to help others grow and become better to make society better" (RMD; 21-23) and "Working together with other teammates towards a common goal" (RMC; 79). The final theme provided evidence of the positive impact of role modelling, particularly through emulation. The adult participants voiced their experiences, as outlined in the following examples: "I am a better person than I thought I am. I have learnt to put myself into other people's shoes to understand how the outside world can be" (RMB 59; 68-70) and "I did not realise we would have such an effect on the 
children... the one girl told me I am her role model which made me want to be a better person" (RMA; 71).

The extracts of the participants shed valuable insight on respective experiences by the children and adults of the RRR project, as outlined in the following two examples.

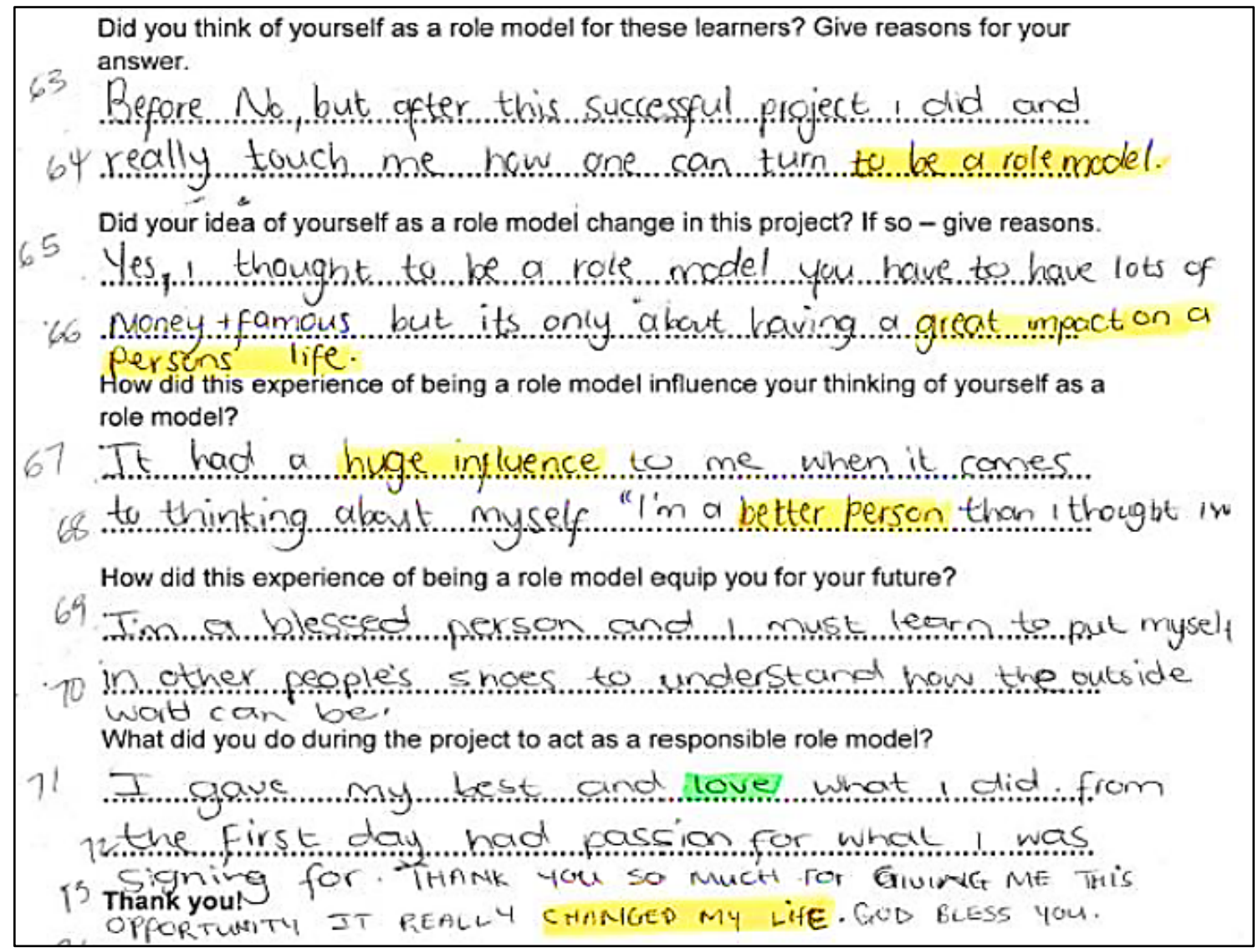

Illustration 3: Example of reflections of the adult participants 


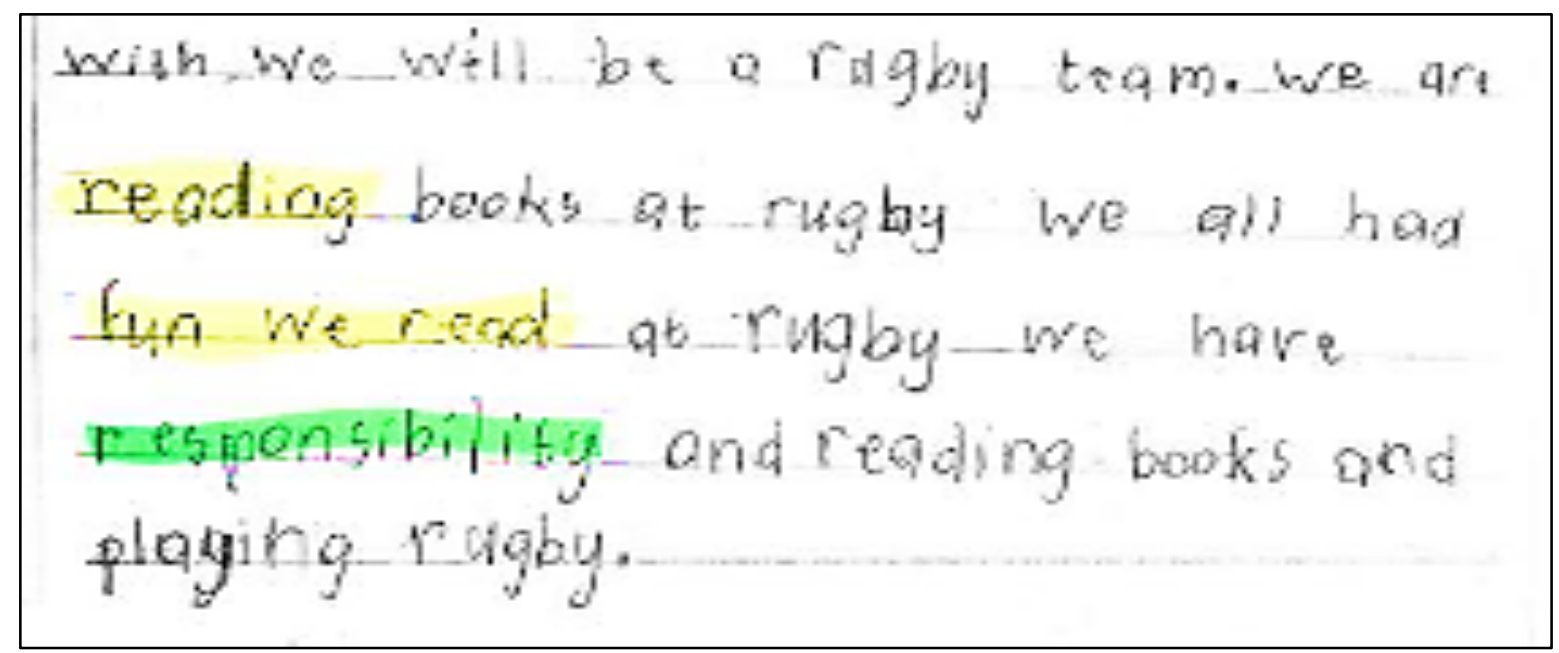

Illustration 4: Example of the accounts of the child participants.

\section{INTERPRETATION OF RESULTS AND DISCUSSION}

Role models provide a framework for the growth of a child, and participation in sport helps children show responsible behaviour and demonstrate maximum sensitivity and responsiveness to the wellbeing of others (Hellison, 2011). Marshalling and aligning the RRR project with the Col framework, we developed an improved understanding of the importance of introducing a mindful role model to a learning experience to promote social, cognitive and teaching presences.

The adult participants felt that it was important for young children to have role models whom they can look up to for guidance while developing a sense of citizenship and responsibility through playing rugby and reading books. The importance of creating a social presence is evident in the adults' feedback in theme four, seeing that the learning experience is shared with other mindful role models, and as a Col, they collaborated to attain the communal goal of teaching social and academic responsibility to the children. Being vested in the presence of a role model while playing rugby and reading books links with pro-social behaviour (Kavussanu, 2006). It also emulates responsible behaviour that extends beyond the sports fields (Hellison, 2011) and encourages children to read because they value the input of role models (Clare et al., 2009). 
Our study provided additional support for the importance of a "cognitive presence". Zirkel (2002) states that young children pursue only that which they can imagine possible. Thus, it is the modelling of responsible behaviour and goal attainment that motivates children's sense of opportunity. The empirical data in theme two attests that the sports students inspired the young children to develop values and responsibility through role modelling. Being exposed to a mindful role model not only imbues other children with the belief that they too can achieve that excellence but also reveals how to transfer and sustain life skills and recognise role model qualities in others and themselves (Camiré et al., 2012; Eley \& Kirk, 2002). The quotations of the child participants in theme three concurred with the notion of Clare et al. (2009) that children need role models to enhance their reading and comprehension skills (Clarke et al., 2009), while also developing a sense of citizenship and values (Gordon, 2010). The children benefitted from mindful role models who helped them to read and conversed with them to improve their understanding and fluency (see Illustration 1). Therefore, a change in educational practices is needed to give the role models the opportunity to integrate physical activities with reading activities to construct respect and responsibility progressively in our young citizens in a democratic society.

The contribution of Bandura's work to early childhood pedagogies is significant for creating a "teaching presence". Bandura $(1977,1986)$ emphasises that children learn from role models and indicates how the observed behaviour can be imitated or emulated. The latter was evident in theme two and three of the narratives of the children and the reflections of the adult participants from theme five. It is significant to have role models in the continuum of child development (Bee \& Boyd, 2004), beckoning their value to be utilised as a teaching approach or resource. Children being confronted with diverse social and educational environments and interaction with a mindful role model signals a possible learning experience. We also argue that there is not only one overriding influence in the life of a child but rather, the sum of the interactions with role models is integral in developing the self-concept and self-efficacy beliefs of the child (Bandura, 1977, 1986; Bee \& Boyd, 2004). This we have demonstrated by implementing the RRR project over eight weeks. 


\section{H. DU PREEZ ET AL.}

\section{CONCLUSION}

The evidence from the RRR project points towards the notion that the child participants were able to display acceptable social and academic behaviour when they were exposed to mindful and responsible role models whom they could emulate. The findings add to the growing body of scholarship on the notion that engaging in a team sport, such as rugby, under the guidance of a mindful role model, coupled with educational outcomes, plays a vital role in early childhood development and education. Taken together, the results seem to suggest that interacting with the rugby role models, and their peers enhanced the children's realisation of values, such as respect, responsibility and becoming responsible citizens. The insight we have gained from the RRR project has also enhanced our understanding of how role modelling can be effectively utilised as a hybrid pedagogy and a rich resource. The Col framework, which characterises a social, cognitive and teaching presence, warrants a learning experience where the child can come to understand what quality, knowledge or skill is possessed by the role model, which is worthy of being valued and emulated. Although this study highlighted results that had been achieved through contact role modelling, the social, cognitive and teaching presences of the Col framework can also be achieved at a distance and need to be further examined in early childhood teaching education pedagogies. Our data suggest that the RRR project, aligned with the Col framework, can guide teachers in creatively constructing future learning experiences that draw on communities of real-life and virtual role models.

\section{ACKNOWLEDGEMENTS}

This article is based on the MEd dissertation of Francinah Masola entitled "Sport students" experiences of role modelling when teaching responsibility to Grade 3 learners", under the supervision of Prof Ina Joubert and Dr Donna Hannaway, University of Pretoria.

\section{Disclosure statement}

No potential conflict of interest was reported by the authors. 


\section{Notes on contributors}

Hannelie du Preez, is lecturer in the Department of Early Childhood Education Faculty of Education University of Pretoria.

Donna Hannaway, is Senior Lecturer in the Department of Early Childhood Education, School of Teacher Education, University of South Africa.

Ina Joubert serves at present as Executive Academic Director of SANTS; a Private Higher Education Institution.

Francinah Masola, is a student in the Department of Early Childhood Education, Faculty of Education University of Pretoria.

\section{ORCID}

Hannelie du Preez http://orcid.org/0000-0003-1194-427X

Donna Hannaway https://orcid.org/0000-0001-6517-0607

\section{REFERENCES}

Allenders, S, Cowburn, G \& Foster, C. 2006. Understanding participation in sport and physical activity among children and adults. Journal of Health Education Research, 21(6):826-835. DOI: https://doi.org/10.1093/her/cyl063

Bandura, A. 1977. Social learning theory. Englewood Cliffs, NJ: Prentice Hall.

Bandura, A. 1986. Social foundations of thought and action: A Social Cognitive Theory. Englewood Cliffs, NJ: Prentice Hall.

Bee, H \& Boyd, D. 2004. The developing child (11th ed.). Boston, MA: Allan \& Bacon.

Camiré, M, Trudel, P \& Forneris, T. 2012. Coaching and transferring life skills:

Philosophies and strategies used by model high school coaches. The Sport Psychologist, 26(2):243-260. DOI: https://doi.org/10.1123/tsp.26.2.243

Clarke, C, Osborne, S \& Dugdale, G. 2009. Reaching out with role models. London: National Literacy Trust.

Denzin, N \& Lincoln, Y. 2008. Collecting and interpreting qualitative material (3rd ed.). London: SAGE Publications.

Department of Basic Education. 2011. Curriculum assessment policy statement (CAPS) Grade R-3. Pretoria: Government Printers. 
Eley, D \& Kirk, D. 2002. Developing citizenship through sport: The impact of a sportbased volunteer programme on youth sport leaders. Journal of Sport, Education and Society, 7(2):151-166. https://doi.org/10.1080/1357332022000018841

French, J \& Pena, S. 1991. Children's hero play of the 20th century: Changes resulting from television's influence. Child Study Journal, 21(2):79-95.

Garrison, DR. 2007. Online Community of Inquiry review: Social, cognitive and teaching presence issues, Journal of Asynchronous Learning Networks, 11(1): 61-72.

Garrison, DR, Anderson, T \& Archer, W. 2000. Critical inquiry in a text-based environment: Computer conferencing in higher education. The Internet and Higher Education, 2(2-3):87-105. DOI: https://doi.org/10.1016/S1096-7516(00)00016-6

Gordon, B. 2010. An examination of the responsibility model in a New Zealand secondary school physical education program. Journal of Teaching in Physical Education, 29(1):21-37. DOI: https://doi.org/10.1123/itpe.29.1.21

Gould, D \& Carson, S. 2008. Life skills development through sport: Current status and future directions. International Review of Sport \& Exercise Psychology, 1(1):58-78. DOI: https://doi.org/10.1080/17509840701834573

Gould, D, Collins, K, Lauer, L \& Chung, Y. 2007. Coaching life skills through football: A study of award winning high school coaches. Journal of Applied Sport Psychology, 19:16-37. DOI: https://doi.org/10.1080/10413200601113786.

Hellison, D. 2011. Teaching personal and social responsibility through physical activity (3rd ed.). Champaign, IL: Human Kinetics.

Kavussanu, M. 2006. Motivational predictors of prosocial and antisocial behaviour in football. Journal of Sports Sciences, 24(6):575-588. DOI: https://doi.org/10.1080 $\underline{102640410500190825}$

Laker, A. 2000. Beyond the boundaries of physical education. Educating young people for citizenship and social responsibility. London: Routledge.

Sanderse, W. 2013. The meaning of role modelling in moral and character education. Journal of Moral Education, 42(1):28-42. DOI: https://doi.org/10.1080 103057240.2012.690727

Owens, K. 2002. Child and adolescent development. An integrated approach. London: Belmont. 
Payne, W, Reynolds, M, Brown, S \& Fleming, A. 2014. Sports role models and their impact on participation in physical activity: A literature review. University of Ballarat, Australia.

Zirkel, S. 2002. Is there a place for me? Role models and academic identity among white students and students of color. Teachers College Record, 104(2):357-376. 